\title{
Econometric Analysis on Development of Grain Industry in Zhanjiang
}

\author{
Yanli $\mathrm{Xu}^{1,3}$, Dan $\mathrm{Liu}^{2,3,{ }^{*}}$ and Zixin $\mathrm{Wu}^{3}$
}

\author{
${ }^{1}$ School of Business, Lingnan Normal University, Zhanjiang, Guangdong, 524048, P. R. China \\ ${ }^{2}$ Liabrary, Lingnan Normal University, Zhanjiang, Guangdong, 524048, P. R. China \\ ${ }^{3}$ South China Sea Silk Road Collaborative Innovation Centre, Lingnan Normal University \\ ${ }^{*}$ Corresponding author: liudan100liudan@163.com
}

Keywords: Grain total output; Applying quantity of agricultural chemical fertilizer; Grain acreage

\begin{abstract}
In order to increase the total grain output in Zhanjiang, this paper uses econometrics method to establish the regression model of grain yield in Zhanjiang, and analyzes the factors such as the amount of chemical fertilizer affecting the grain yield of Zhanjiang and the cultivated area of grain crops. The research shows that the amount of chemical fertilizer and grain sown area are the main factors affecting the grain yield in Zhanjiang. Therefore, it can be concluded that the amount of chemical fertilizer is the most significant factor affecting Zhanjiang's total grain output and that the farmers benefit most from agricultural inputs. The cultivated area of food crops is also one of the important factors that affect the total output of grain. Crop acreage is an effective way to increase grain output.
\end{abstract}

\section{Introduction}

Food is the most basic consumer goods for life. The food issue of a country is a top priority for its own national economy and people's livelihood. Agriculture is the basis for the development of the national economy. Food is the foundation of the foundation. Therefore, food production is an eternal theme related to the survival and development of a country. Since the founding of our country, the grain output has fluctuated many times. This not only restricts the development of the national economy, but also has extremely adverse effects on both grain producers and consumers.

Zhanjiang is an agricultural market and a large consumer market. The city's total population is 7.1599 million, of which agricultural population is 5.1508 million, accounting for $71.9 \%$. As the population continues to grow, the problem of food shortages is worsening. Therefore, it is still very important to ensure the basic consumption needs of local foodstuffs. We must pay close attention to food security. Through the study of grain yield in Zhanjiang, we can know what factors are affecting grain production in Zhanjiang and their degree of impact.

In order to increase the total grain output in Zhanjiang, this paper uses econometrics method to establish the regression model of grain yield in Zhanjiang, and analyzes the factors such as the amount of chemical fertilizer affecting the grain yield of Zhanjiang and the cultivated area of grain crops. The research shows that the amount of chemical fertilizer and grain sown area are the main factors affecting the grain yield in Zhanjiang. Therefore, it can be concluded that the amount of chemical fertilizer is the most significant factor affecting Zhanjiang's total grain output and that the farmers benefit most from agricultural inputs. The cultivated area of food crops is also one of the important factors that affect the total output of grain. Crop acreage is an effective way to increase grain output.

\section{Model Setting and Data Description}

Table 1 shows the statistical data obtained from Zhanjiang statistical information website. 
Table 1 Grain output, applying quantity of agricultural chemical fertilizer and grain acreage etc of Zhanjiang

\begin{tabular}{|c|c|r|r|r|}
\hline Year & $\begin{array}{c}\text { Grain } \\
\text { output }(\mathrm{t}) \\
Y\end{array}$ & $\begin{array}{c}\text { Applying quantity of agricultural } \\
\text { chemical fertilize (t) } X_{1}\end{array}$ & $\begin{array}{c}\text { Grain acreage } \\
(\mathrm{mu}) X_{2}\end{array}$ & $\begin{array}{c}\text { Total power of agricultural } \\
\text { machinery (KW) } X_{3}\end{array}$ \\
\hline 2001 & 1275713 & 350077 & 4274354 & 1959889 \\
\hline 2002 & 1376055 & 354757 & 4299236 & 2048478 \\
\hline 2003 & 1388662 & 356972 & 4317529 & 2134059 \\
\hline 2004 & 1413023 & 370917 & 4320514 & 2394399 \\
\hline 2005 & 1424295 & 377682 & 4364597 & 2570982 \\
\hline 2006 & 1428370 & 406721 & 4366780 & 3432319 \\
\hline 2007 & 1475668 & 417979 & 4380454 & 3824919 \\
\hline 2008 & 1477627 & 421886 & 4387671 & 4360508 \\
\hline 2009 & 1481592 & 424829 & 4565388 & 4710263 \\
\hline 2010 & 1487981 & 430183 & 4599010 & 4792941 \\
\hline 2011 & 1525757 & 438838 & 4613882 & \\
\hline 2012 & 1540379 & 453551 & 4635882 & \\
\hline 2013 & 1551099 & 454216 & 4651428 & \\
\hline
\end{tabular}

As can be seen from Table 1, grain output in Zhanjiang has been increasing year by year, from 1275713 tons in 2001 to 1551099 tons in 2013.

The main factors affecting the grain yield in Zhanjiang are the amount of agricultural and chemical fertilizers applied, the sown area of grain and the total power of agricultural machinery.The following model is set up in this regard:

$$
Y_{t}=\beta_{0}+\beta_{1} X_{t 1}+\beta_{2} X_{t 2}+\beta_{3} X_{t 3}+\mu_{t}, \quad t=1,2, \cdots, 13
$$

Among them, $Y_{t}$ is the grain production in the $t$ year (tons), $X_{1}$ is the amount of fertilizer for agriculture (tons), $X_{2}$ is the sown area of grain (mu), and $X_{3}$ is the total power of agricultural machinery $(\mathrm{kw})$.

\section{Estimation and Examination of Model Parameters}

By virtue of Eview software, the regression results between food production $Y$ and its impact factors $X_{1}, X_{2}$ and $X_{3}$ can be derived as follows: 


\begin{tabular}{|c|c|c|c|c|}
\hline Variable & Coefficient & Std. Error & t-Statistic & Prob. \\
\hline $\mathrm{C}$ & -67999.65 & 1293576. & -0.052567 & 0.9592 \\
\hline $\mathrm{X} 1$ & 1.852528 & 0.652250 & 2.840213 & 0.0194 \\
\hline $\mathrm{X} 2$ & 0.188841 & 0.307755 & 0.613608 & 0.5547 \\
\hline $\mathrm{X} 3$ & -0.022125 & 0.047951 & -0.461414 & 0.6555 \\
\hline R-squared & 0.881741 & \multicolumn{2}{|c|}{ Mean dependent var } & 1449709. \\
\hline Adjusted R-squared & 0.842322 & \multicolumn{2}{|c|}{ S.D. dependent var } & 76426.53 \\
\hline S.E. of regression & 30348.00 & \multicolumn{2}{|c|}{ Akaike info criterion } & 23.72651 \\
\hline Sum squared resid & $8.29 E+09$ & \multicolumn{2}{|c|}{ Schwarz criterion } & 23.90034 \\
\hline Log likelihood & -150.2223 & \multicolumn{2}{|c|}{ Hannan-Quinn criter. } & 23.69078 \\
\hline F-statistic & 22.36812 & \multirow{2}{*}{\multicolumn{2}{|c|}{ Durbin-Watson stat }} & 1.501223 \\
\hline Prob(F-statistic) & 0.000165 & & & \\
\hline
\end{tabular}

Figure 1 Regression results of food production and impact factors from 2001 to 2013 in Zhanjaing

The regression results show that the regression model is as follows

$$
\hat{Y}=-67999.65+1.852528 X_{1}+0.188841 X_{2}-0.022125 X_{3}
$$

In the above equation, the sign of the coefficient of agricultural machinery total power $X_{3}$ is negative, which iscontrary to common sense, so $X_{3}$ should be removed.

The regression is conducted again and the regression equation is obtained:

$$
\hat{Y}=493517.2+1.678476 X_{1}+0.062380 X_{2}
$$

\section{Result}

The results of the model estimation show that for every 1 ton increase of agro-chemical fertilizer application, on the assumption that other variables are unchanged, the average grain output will be increased by 1.68 tons. When the other variables are unchanged, when the sown area of grain is increased by $1 \mathrm{mu}$, the average grain output will increase 0.06 tons.

\section{Conclusion}

Through the analysis of the influencing factors of grain yield in Zhanjiang from 2001 to 2013, we can draw the following conclusions: The grain yield of Zhanjiang is affected by the amount of chemical fertilizer and grain sown area. It can be seen from the model that the amount of chemical fertilizer is the most significant factor affecting the increase of grain output in Zhanjiang, which shows that in the current agricultural production, farmers have the most benefit from the investment in agriculture. The cultivated area of food crops is also one of the important factors affecting the total output of grain. To expand the cultivated area of food crops is an effective way to increase grain output.

\section{Acknowledgements}

It is a pleasure to acknowledge the support of the project from XU Yan-li being selected in the introduction of shortage top talent of "Sailing up (Yangfan) project" in Guangdong Province in 2014. The project is Leading Industry Development Strategy Research in Emerging Areas in Western Guangdong for Accelerating the Economic Development of Western Guangdong. 
It is a pleasure to acknowledge the support from the talents introduction project of universities in Guangdong Province and from Guangdong University of Petrochemical Technology. The project is the Coordinating Development Model Construction and the Path Research of Technical Capability and Technology Management Capability in Equipment Manufacturing Industry.

It is a pleasure to acknowledge the support from the talents introduction project of Guangdong University of Petrochemical Technology. The project is Research on the Coordinating Development Model and Path of Technical Capability and Technology Management in Maoming (513088).

It is a pleasure to acknowledge the support from comprehensive reform experiment of the Major of International Economics and Trade in Guangdong University of Petrochemical Technology.

It is a pleasure to acknowledge the support from International Education Department in Guangdong University of Petrochemical Technology. The project is Research on Teaching Quality Evaluation for the Major of International Economics and Trade in English in the Background of International Education (2014GDUPTGJ-07).

It is also a pleasure to acknowledge the support from South China Sea Silk Road Collaborative Innovation Center in Lingnan Normal University (2017EL03).

It is also a pleasure to acknowledge the support from Excellent Course "Macroeconomics" in Teaching Quality and Teaching Reform Project in Lingnan Normal University in 2017 (114961700227).

\section{Reference}

[1] Wang Yingming, Huang Jiyuan. Decrease Cause and Cultivation Channels of Soil Fertility in Zhanjiang Area

[2] Jiang Heping. Characteristics and Models of Modern Agricultural Construction in China. China Development Observation[J]. 2007, 02

[3] Kong Xiangzhi, Li Shengjun. On the Development Mode of Modern Agriculture in China. Teaching and Research[J]. 2007, 10

[4] Liang Jian . Study on Standardized Production of Non-polluted Tea Cultivation in Maoming City. Jilin Agriculture[J]. 2017

[5] Zhang Mu, Tang Shuanhu. Effects of Different Nitrogen Fertilizers and Application Methods on Nutrient Absorption Characteristics and Yield Formation of Rice. Soil and Fertilizer Sciences[J]. 2017 